\title{
Burden of Noncommunicable Diseases and National Strategies to Control Them in Korea
}

\author{
Young-Ho Khang \\ Department of Preventive Medicine, University of Ulsan College of Medicine, Seoul, Korea
}

Noncommunicable diseases (NCDs) are the most important causes of premature mortality and disability-adjusted life years in Korea. NCDs are also the main contributor to socioeconomic inequalities in mortality and life expectancy. Reduction of NCDs and NCD inequalities would result in significant improvement in healthy life expectancy and health equity in Korea. Major NCD risk factors such as dietary risks (including salt intake), alcohol consumption, cigarette smoking, and high blood pressure were found to be the leading modifiable risk factors of disability-adjusted life years in Korea, based on the 2010 Global Burden of Disease Study. Several Korean studies have shown that these risk factors play an important role in creating socioeconomic inequalities in NCD mortality and total mortality. Current international discussions on NCD policies in the United Nations and the World Health Organization would provide better opportunities for developing aggressive population-wide policy measures in Korea. Considering the paucity of population-wide policies to control major NCD risk factors in Korea, rigorous population approaches such as taxation and regulation of unhealthy commodities as well as public education and mass campaigns should be further developed in Korea.

Key words: Alcohol drinking, Diet, Korea, Noncommunicable disease, Policy, Smoking

\section{INTRODUCTION: WHY NONCOMMUNICA- BLE DISEASE?}

Globally, noncommunicable diseases (NCDs), mainly cancer, cardiovascular diseases (CVD), chronic obstructive pulmonary diseases (COPD), and diabetes mellitus (DM), are the most important causes of deaths and disability-adjusted life years (DALYs) $[1,2]$. As of $2010,65 \%$ of total deaths in the world were

Received: July 1, 2013 Accepted: July 15, 2013

Corresponding author: Young-Ho Khang, MD, PhD

88 Olympic-ro 43-gil, Songpa-gu, Seoul 138-736, Korea

Tel: +82-2-3010-4290, Fax: +82-2-477-2898

E-mail:youngk@amc.seoul.kr

This is an Open Access article distributed under the terms of the Creative Commons Attribution Non-Commercial License (http://creativecommons.org/licenses/bync/3.0/) which permits unrestricted non-commercial use, distribution, and reproduction in any medium, provided the original work is properly cited. attributable to NCDs (34.5 million of 52.8 million deaths) [1]. According to the 2010 Global Burden of Disease (GBD) study, NCDs caused $54 \%$ of DALYs worldwide [2]. A recent analysis also showed that NCDs accounted for more than half of total mortality in all regions except for Sub-Saharan Africa [3]. It is expected that NCDs will be the major causes of death in SubSaharan Africa by 2030 [4]. Based on age-standardized mortality rates, mortality for most NCDs is higher in low-income and middle-income countries than in high-income countries [3]. Studies on within-country inequalities in mortality indicated that socioeconomically disadvantaged groups had greater mortality rates than their counterparts for most NCDs except for certain causes such as breast cancer and colon cancer [3]. These results on within-country and between-country inequalities challenge a popular view that NCDs are diseases of affluence and westernization [3]. In fact, $80 \%$ of all NCD deaths in the world occur in low- and middle-income countries [5]. 


\section{INTERNATIONAL ACTIONS ON NONCOMMU- NICABLE DISEASES}

Many important international actions on NCDs have been initiated through international agencies including the United Nations (UN) and the World Health Organization (WHO) during the past decade (Table 1). The Global Strategy for NCD Prevention and Control was first adopted by the 53rd World Health Assembly (WHA) in 2000 and asked the WHO DirectorGeneral to continue giving priority to NCD prevention and control. The WHO made important steps toward controlling major NCD risk factors by adopting the Framework Convention on Tobacco Control, the Global Strategy on Diet, Physical Activity and Health, and the Global Strategy to Reduce Harmful Use of Alcohol in 2003, 2004, and 2010, respectively. Based on the 2007 resolution calling for concrete action on NCDs, the WHA passed a resolution endorsing the Action Plan for the Global Strategy for the Prevention and Control of Noncommunicable Diseases in 2008. The Action Plan set out six objectives, actions to be implemented over the six-year period of 2008 to

Table 1. Major international activities on NCDs since 2000

\begin{tabular}{|c|c|}
\hline $\begin{array}{l}\text { Calendar } \\
\text { year }\end{array}$ & International activities \\
\hline 2000 & $\begin{array}{l}\text { Resolution in the WHA on Prevention and Control of } \\
\text { Noncommunicable Diseases (WHA53.17) }\end{array}$ \\
\hline 2003 & WHO Framework Convention on Tobacco Control \\
\hline 2004 & $\begin{array}{l}\text { Global Strategy on Diet, Physical Activity and Health endorsed } \\
\text { by the WHA }\end{array}$ \\
\hline 2007 & $\begin{array}{l}\text { Resolution WHA60.23 on Prevention and Control of } \\
\text { Noncommunicable Disease: Implementation of the Global } \\
\text { Strategy }\end{array}$ \\
\hline 2008 & $\begin{array}{l}\text { WHO Report on the Global Tobacco Epidemic, } 2008 \text { - The } \\
\text { MPOWER Package } \\
\text { Resolution WHA61.14 on 2008-2013 Action Plan for the Global } \\
\text { Strategy for the Prevention and Control of Noncommunicable } \\
\text { Diseases }\end{array}$ \\
\hline 2009 & Creation of the Non-communicable Disease Network \\
\hline 2010 & $\begin{array}{l}\text { UN General Assembly resolution calling for a high-level } \\
\text { meeting on NCDs } \\
\text { Global Strategy to Reduce the Harmful Use of Alcohol } \\
\text { Establishment of the NCD Alliance }\end{array}$ \\
\hline 2011 & $\begin{array}{l}\text { Political Declaration on NCDs by the UN NCD High-level } \\
\text { Summit } \\
\text { WHO Global Status Report on Noncommunicable Diseases } 2010 \\
\text { WHO Noncommunicable Diseases Country Profiles } 2011\end{array}$ \\
\hline 2012 & $\begin{array}{l}\text { Mortality target - the } 25 \text { by } 25 \text { goal adopted by the WHA } \\
\text { Rio+20 UN Conference on Sustainable Development }\end{array}$ \\
\hline 2013 & $\begin{array}{l}\text { 2013-2020 NCD Global Action Plan and the Global Monitoring } \\
\text { Framework for NCDs endorsed by the WHA }\end{array}$ \\
\hline
\end{tabular}

NCD, noncommunicable disease; WHA, World Health Assembly; WHO, World Health Organization; UN, United Nations.
2013, and performance indicators [6]. Subsequently the Global Noncommunicable Disease Network (NCDnet) supported by the WHO was created for WHO member states, the WHO itself, international partners, and other stakeholders to promote partnerships for the prevention and control of NCDs [7]. In 2010, the NCD Alliance was founded by four international nongovernmental federations representing the four main NCDs [8]. The NCD Alliance now represents over 2,000 civil society organizations in more than 170 countries and acts as a positive initiative for cooperation to combat the NCD epidemic by putting health at the center of all governmental policies [8]. Based on the 2010 UN General Assembly resolution calling for a high-level meeting on NCDs, the NCD High-level Summit was held in New York in September 2011. This summit was the second UN General Assembly meeting devoted to a global health topic, following the 2001 UN General Assembly Special Session dedicated to HIV/AIDS. In 2012, the WHA endorsed a goal for the reduction of NCDs: to reduce avoidable mortality from NCDs by $25 \%$ by 2025 (the 25 by 25 goal). In the recent WHA in May 2013, the 2013-2020 NCD Global Action Plan and the Global Monitoring Framework for NCDs were endorsed. The Global Monitoring Framework included nine global targets and 25 voluntary indicators [9].

It has been also argued that NCDs should be embedded in the post-2015 development agenda [10]. This is because NCDs are leading causes of death and disability and subsequently impair sustainable development through their impacts on the societal, economic, and environmental domains [10]. According to a recent estimation, tobacco use annually costs $1 \%$ to $2 \%$ of the global gross domestic product (GDP) [11]. A recent study by the World Economic Forum and Harvard University estimated that NCDs will cost the world economy $\$ 47$ trillion over the next 20 years, representing $75 \%$ of the global GDP and surpassing the cost of the global financial crisis [12]. In a similar vein, the 2012 UN Conference on Sustainable Development, Rio+20, acknowledged that the NCD burden constitutes "one of the major challenges for sustainable development in the 21st century" [13], emphasizing the relationship between the NCDs and development.

\section{BURDEN OF NONCOMMUNICABLE DISEASES IN KOREA}

NCDs accounted for $82 \%$ of the total deaths in 2008 in South Korea (hereafter 'Korea') [14]. Based on the recent GBD study, 
many NCDs were included in the 10 leading health problems causing the burden of disease measured by years of life lost: stroke, ischemic heart disease, liver cancer, stomach cancer, lung cancer, liver cirrhosis, diabetes, and colorectal cancer [15]. NCDs including stroke, low back pain, DM, ischemic heart disease, liver cancer, other musculoskeletal disorders, stomach cancer, and neck pain were in the top 10 causes of DALYs in 2010 in Korea (Table 2) [15]. In Korean men, the burden of liver cancer, self-harm, road injury, lung cancer, and liver cirrhosis were relatively great while in women musculoskeletal disorders, neck pain, major depressive disorders, anxiety disorders, and migraine were important causes of DALYs. Using mortality and national health insurance claim data in Korea, researchers also found that the four major NCDs (cancer, CVD, DM, and COPD) were important contributors to years of life lost and DALYs $[16,17]$.

The importance of NCDs has been recognized by the Korean

Table 2. The 20 most important causes of disability-adjusted life years in Korean men and women: findings of the Global Burden of Diseases, Injuries, and Risk Factors Study 2010

\begin{tabular}{|c|c|c|c|}
\hline Rank & Both genders & Men & Women \\
\hline 1 & Stroke & Stroke & Stroke \\
\hline 2 & Low back pain & Liver cancer & Low back pain \\
\hline 3 & Diabetes & Low back pain & Other musculoskeletal \\
\hline 4 & Ischemic heart disease & Self-harm & Diabetes \\
\hline 5 & Self-harm & Road injury & Neck pain \\
\hline 6 & Liver cancer & Diabetes & Ischemic heart disease \\
\hline 7 & Other musculoskeletal & I Lung cancer & $\begin{array}{l}\text { Major depressive } \\
\text { disorder }\end{array}$ \\
\hline 8 & Road injury & Ischemic heart disease & Anxiety disorders \\
\hline 9 & Stomach cancer & Stomach cancer & Migraine \\
\hline 10 & Neck pain & Cirrhosis & Self-harm \\
\hline 11 & Lung cancer & Falls & Stomach cancer \\
\hline 12 & $\begin{array}{l}\text { Major depressive } \\
\text { disorder }\end{array}$ & Alcohol use disorders & Alzheimer's disease \\
\hline 13 & Cirrhosis & Neck pain & Falls \\
\hline 14 & Falls & Other musculoskeletal & Osteoarthritis \\
\hline 15 & Anxiety disorders & COPD & Road injury \\
\hline 16 & Migraine & Colorectal cancer & Lung cancer \\
\hline 17 & Alcohol use disorders & $\begin{array}{l}\text { Major depressive } \\
\text { disorder }\end{array}$ & Liver cancer \\
\hline 18 & Colorectal cancer & Drug use disorders & COPD \\
\hline 19 & COPD & Anxiety disorders & Colorectal cancer \\
\hline 20 & Alzheimer's disease & Migraine & Breast cancer \\
\hline
\end{tabular}

From Institute for Health Metrics and Evaluation. GBD arrow diagram [Internet] [15].

COPD, chronic obstructive pulmonary disease. government, while it sometimes issues official documents on disease trends not backed by scientific evidence. For example, it was asserted in a white paper of the Ministry of Health and Welfare that chronic disease mortality rates are rapidly increasing in Korea [18]. This, however, is misleading, considering that Korea recorded a huge increase in life expectancy during the past several decades, mainly due to the reduction of NCD mortality (especially CVD mortality) [19]. The increasing importance of NCDs in population health does not mean increases in NCD mortality. As indicated in a recent Science paper, mortality from major NCDs (CVD, COPD, and even some cancers) has declined or shifted to older ages, but this occurred later and more slowly than decreases in mortality from infectious diseases [20]. Thus, the relative importance of NCDs can be better explained by differences in the speed of mortality reduction between NCDs and infectious diseases, rather than an absolute increase in NCD mortality.

Figure 1 supports this explanation. Figure 1 presents trends in age-standardized mortality rates (with the world standard population being the referent), crude mortality rates, and numbers of all-cause and NCD deaths by age group in Korea between 1983 and 2011. Age-standardized mortality rates for NCDs declined during the past decades. This decline was CVD, the leading NCD in Korea. However, of all-cause mortality rates, the proportion of mortality rates from the four major NCDs (cancer, CVD, DM, and COPD) was 39.4\% in 1983 but increased to $56.0 \%$ in 2011 . Although crude cancer mortality rates are increasing, crude NCD mortality rates have shown rather stable trends during the past decade. Differences between age-standardized and crude mortality rates would be mainly due to population ageing. As seen in (C) and (D) of Figure 1 , similar numbers of all-cause deaths were recorded during the past three decades. However, the number of deaths from the four major NCDs has increased, and this increase was mainly due to the increase in the numbers of NCD deaths among those aged 65 or over. Figure 1 also shows that mortality from communicable diseases (infectious and parasitic diseases and acute respiratory infection) accounted for only a small part of total mortality over the period between 1983 and 2011. A detailed analysis indicated that mortality from infectious and parasitic diseases (International Classification of Diseases 10th revision [ICD-10] code: A00-B99) substantially decreased during the period while mortality from acute respiratory infection (ICD-10 code: J09-J22) among the elderly population recently increased (data not shown here). 

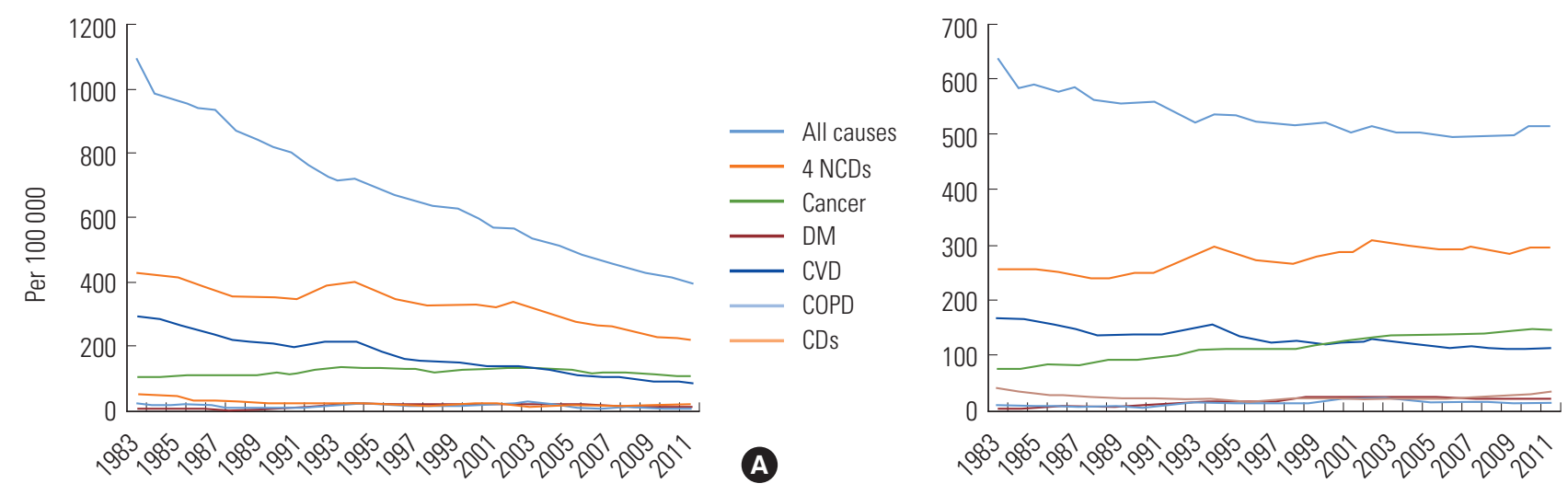

B
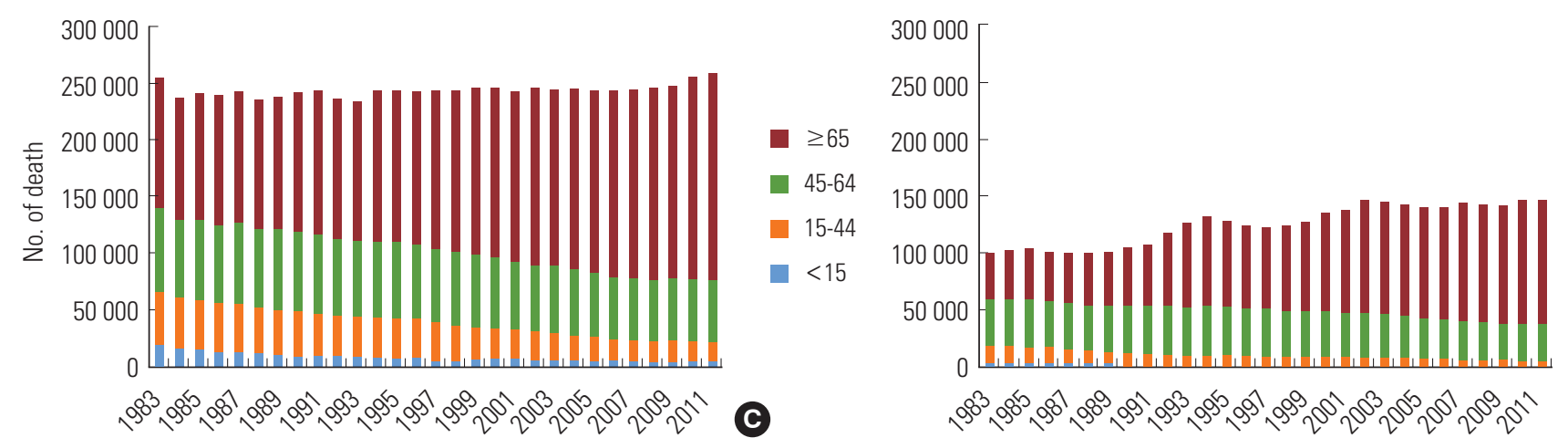

Figure 1. Trends in age-standardized mortality rates (A), crude mortality rates (B), numbers of all-cause deaths by age group (C), and numbers of deaths from four major noncommunicable diseases (NCDs) by age group in Korea, 1983 to 2011 (D). The agestandardized mortality was calculated with the world standard population as the referent. The four NCDs refer to cancer (International Classification of Diseases 10th revision [ICD-10] code C00-D48), cardiovascular disease (CVD, ICD-10 code 100-199), diabetes mellitus (DM, ICD-10 code E10-E14), and chronic obstructive pulmonary disease (COPD, ICD-10 code J40-J47). CD, communicable disease (ICD-10 code A00-B99, J09-J22).

The morbidity data should be also examined. The time trends of the prevalence of NCDs and their risk factors vary by the outcome analyzed. While body mass index showed increasing trends in both genders according to the Global Burden of Metabolic Risk Factors of Chronic Diseases study, decreasing trends were found in systolic blood pressure and fasting blood glucose in Korea [14]. Meanwhile, cancer prevalence and incidence show clear increasing trends. Based on the cancer registry data in Korea [21], the number of cancer incident cases and the crude incidence rate doubled between 2000 and 2010. The age-standardized incidence rate also rose by $42 \%$ during those ten years. These increases in cancer incidence and prevalence were more evident in women than men [21]. A recent cause-specific analysis of cancer registry data also showed that increasing trends in incidence were found for thyroid cancer, colorectal cancer, prostatic cancer (for men), and breast cancer (for women) [22]. Because of the lack of a nationwide active surveillance system for CVD, national health insurance claims data has been used to present time trends of the incidence of two major CVD, ischemic heart disease and stroke, in Korea $[23,24]$. These data showed increasing trends between the mid-1990s and mid-2000s [23], but decreasing trends afterward since the mid-2000s [24]. No significant increasing trends were found for diabetes prevalence based on the data from the Korea National Health and Nutrition Examination Survey (KNHANES) between 1998 and 2009 [25]. However, according to a review of community surveys on diabetes prevalence, it was concluded that the prevalence of diabetes in Korea has increased six- to seven-fold in the past 40 years [25]. For COPD, population-based spirometric surveys have been included as a component of the KNHANES in 2001 and 2008. Survey results show that the prevalence of COPD among participants aged 40 or over was $17.2 \%$ in 2001 [26] and 13.4\% in 2008 [27]. The decreasing tendency between 2001 and 2008 is, however, 
thought to be due to different criteria for spirometry rather than an actual decrease in the prevalence of COPD [27].

\section{SOCIOECONOMIC INEQUALITIES IN NON- COMMUNICABLE DISEASES IN KOREA}

Socioeconomic inequalities in NCDs and NCD risk factors have been demonstrated in government reports and epidemiological studies in Korea. Using census and mortality data, educational inequalities in mortality have been identified for most NCDs except for ischemic heart disease and breast cancer [28]. Longitudinal follow-up data also showed mortality inequalities by income group for most NCDs except for a few cancers (kidney cancer for men and non-Hodgkin's lymphoma for women) [29]. Using cancer registry and health insurance data, socioeconomic inequalities in cancer incidence and cancer survival have been reported in Korea [30,31]. The Ministry of Health and Welfare and the Korea Centers for Disease Control and Prevention have published annual reports, 'Korea Health Statistics', based on the KNHANES and have included age-standardized prevalences or means by income and urbanization levels in a wide range of NCD prevalences, NCD risk factors, and health care utilization rates related to NCDs [32]. Recently, in a special issue of the Journal of the Korean Medical Association on health inequalities, Korean researchers reviewed the prior literature and concluded that socioeconomic inequalities in NCD risk factors and health care utilization related to NCDs are widespread in Korea and the magnitude of the inequalities for some measures is even increasing $[33,34]$.

NCDs are the main contributor to between-country and within-country inequalities in total mortality [3]. A recent analysis examined cause-specific contributions to socioeconomic inequalities in total mortality in England, New Zealand, Korea, and Japan and showed that four major NCDs (cancer, CVD, COPD, and DM) accounted for the major part of mortality inequalities by geographical deprivation index [3]. In this international comparative study, the contribution of NCDs was relatively smaller in Korea than the contribution in the other three industrialized countries. The finding can be explained by the discrepancy in the size of the geographical unit in each country, the lower level of residential segregation in Korea than other countries, and ill-defined causes in Korean death certificate data [3]. Meanwhile, several Korean studies using individual socioeconomic position indicators indicated that NCDs are the main determinants of inequalities in mortality and life ex- pectancy $[29,35]$. For example, in an analysis using mortality linkage data of Korean public servants aged 35 to 64, four major NCDs accounted for $50.4 \%$ and $70.8 \%$ of the absolute inequalities in total mortality of men and women, respectively, as measured by slope indices of inequality [29].

\section{DETERMINANTS OF THE NONCOMMUNICA- BLE DISEASE BURDEN AND ITS INEQUALI- TIES IN KOREA}

Tobacco and alcohol use, salt intake and unhealthy diet, high blood pressure, and physical inactivity and obesity have been reported to be major determinants of NCDs $[5,6,20,36]$. The relative importance of these risk factors in explaining the NCD burden is debatable and thus findings on comparative risk assessment are helpful in understanding the role of NCD determinants. Based on the recent comparative risk assessment of the global burden of disease and injury [37], high blood pressure, smoking, and alcohol use were the three leading risk factors for the global disease burden measured by DALYs. In the same analysis, these three risk factors were also the leading determinants of DALYs in Asia Pacific High Income Countries (Japan, Korea, Brunei, and Singapore) [37]. Considering the population size of the four countries in this region (Japan 128 million, Korea 50 million, Brunei 0.4 million, and Singapore 5.2 million), this result primarily represents findings from Japan and Korea. Comparative risk assessment results from Japan, with which Korea shares similarities regarding causes of death structure and risk factors, are thus informative. According to a Japanese study estimating the impact of 16 risk factors on cause-specific mortality and life expectancy, tobacco smoking and high blood pressure were found to be the two major risk factors for adult mortality and shortened life expectancy [38]. Recently, the Institute for Health Metrics and Evaluation at the University of Washington released GBD country profiles and now provides online access to country-specific results on the burden of disease and comparative risk assessment in terms of death, years of life lost, years lost due to disability, and DALYs [15]. According to the results of the comparative risk assessment, dietary risks (including salt intake), alcohol use, smoking, and high blood pressure were the leading risk factors of DALYs in Korea [15]. Gender-specific results indicated the relative importance of alcohol and smoking in Korean men and high blood pressure in Korean women (Table 3) [15].

Although upstream determinants such as poverty and fi- 
Table 3. Risk factor ranking for the burden of disability-adjusted life-years in Korean men and women: findings of the Global Burden of Diseases, Injuries, and Risk Factors Study 2010

\begin{tabular}{|c|c|c|c|}
\hline Rank & Both genders & Men & Women \\
\hline 1 & Dietary risks & Alcohol use & Dietary risks \\
\hline 2 & Alcohol use & Dietary risks & High blood pressure \\
\hline 3 & Smoking & Smoking & $\begin{array}{l}\text { High fasting plasma } \\
\text { glucose }\end{array}$ \\
\hline 4 & High blood pressure & High blood pressure & High body mass index \\
\hline 5 & $\begin{array}{l}\text { High fasting plasma } \\
\text { glucose }\end{array}$ & $\begin{array}{l}\text { High fasting plasma } \\
\text { glucose }\end{array}$ & Physical inactivity \\
\hline 6 & High body mass index & High body mass index & Smoking \\
\hline 7 & Physical inactivity & Physical inactivity & Ambient PM pollution \\
\hline 8 & Ambient PM pollution & Ambient PM pollution & Alcohol use \\
\hline 9 & Occupational risks & Occupational risks & $\begin{array}{l}\text { Intimate partner } \\
\text { violence }\end{array}$ \\
\hline 10 & Drug use & Drug use & High total cholesterol \\
\hline 11 & High total cholesterol & High total cholesterol & Occupational risks \\
\hline 12 & Lead & Lead & Drug use \\
\hline 13 & $\begin{array}{l}\text { Intimate partner } \\
\text { violence }\end{array}$ & Iron deficiency & Lead \\
\hline 14 & $\begin{array}{l}\text { Childhood sexual } \\
\text { abuse }\end{array}$ & $\begin{array}{l}\text { Low bone mineral } \\
\text { density }\end{array}$ & $\begin{array}{l}\text { Childhood sexual } \\
\text { abuse }\end{array}$ \\
\hline 15 & $\begin{array}{l}\text { Low bone mineral } \\
\text { density }\end{array}$ & $\begin{array}{l}\text { Childhood sexual } \\
\text { abuse }\end{array}$ & $\begin{array}{l}\text { Low bone mineral } \\
\text { density }\end{array}$ \\
\hline 16 & Iron deficiency & Radon & Iron deficiency \\
\hline 17 & Radon & Zinc deficiency & Radon \\
\hline 18 & Sanitation & Sanitation & Sanitation \\
\hline 19 & Zinc deficiency & Ozone & Zinc deficiency \\
\hline 20 & Ozone & Childhood underweight & t Ozone \\
\hline
\end{tabular}

From Institute for Health Metrics and Evaluation. GBD arrow diagram [Internet] [15].

PM, particulate matter.

nancial resources, education, working conditions, housing, living environment, and social policies including health care policies play important roles in the creation and maintenance of health inequalities [39], major modifiable risk factors of NCDs have been considered to be the major proximal determinants of socioeconomic inequalities in NCDs [3]. A prior Korean study showed that behavioral risk factors accounted for a significant magnitude of absolute mortality inequalities [40]. Cigarette smoking explained about $34 \%$ to $42 \%$ of absolute inequalities in all-cause mortality by income group among men aged 30-64 and its explanatory ability was even greater for CVD mortality (47\% to 68\%) [41]. Similar results regarding the role of major established CVD risk factors including smoking were reported in prospective studies from other countries $[42,43]$.

\section{NATIONAL STRATEGIES TO CONTROL NON- COMMUNICABLE DISEASES IN KOREA}

Despite the continuing academic activities and policy development surrounding NCDs, interest in recent international policy development on NCDs has been sparse in both the academic community and policy makers of Korea. For example, except for a small discussion section held by a non-governmental research organization [44], no meaningful public discussion regarding the 2011 UN NCD Summit occurred in 2010 and 2011. It is only recently that the Korean Society for Preventive Medicine held academic meetings on NCDs in 2012 and 2013.

This lack of interest in recent international actions on NCDs is partly because policy makers and academic societies in Korea tend to consider policies and activities discussed among international agencies (the UN and WHO for NCDs) as ones for underdeveloped countries. Policy makers may think that the NCD problems in Korea have already been addressed legislatively by the National Health Promotion Act established in 1995 and that measures to control NCDs are now partly established with support of national health insurance and other NCD screening programs at the community public health centers. There may also be a pessimistic view on NCD policies from non-governmental organizations of Korea, in that fundamental approaches to controlling NCDs can be expected to be discouraged in the NCD policy making processes because of lobbying from associated tobacco, alcohol, salt, and unhealthy food industries as well as pharmaceutical companies. For these reasons, the Korean government may not take the NCD issue seriously, as it did not for the Millennium Development Goals.

Nevertheless, the NCD policies of the international agencies may well allow the Korean government to review its own policies on NCDs and NCD risk factors and provide opportunities to develop more aggressive and population-wide policy measures. International discussions to include NCD targets in the post-2015 development agenda in the UN would be a good platform for drawing attention to the links between NCDs and social, economic, and environmental factors.

Many challenges lie ahead in the development of comprehensive national strategies to control NCDs in Korea (Table 4). Establishment of a rigorous and independent accountability mechanism has been suggested to be critical to ensure that the goal of NCD reduction is on track to be met [45]. At the na- 
Table 4. National strategies to be developed for noncommunicable disease (NCD) control and prevention in Korea

\begin{tabular}{|c|c|}
\hline Policy areas & Specific policies to be developed \\
\hline \multirow[t]{2}{*}{ Accountability mechanisms } & Establishment of national presidential NCD commission \\
\hline & Establishment of a governmental unit for monitoring and evaluation \\
\hline Targets and indicators & Development of national targets and indicators based on the Global Monitoring Framework \\
\hline \multirow[t]{5}{*}{ Governmental policies to be developed } & Aggressive taxation of tobacco and alcohol \\
\hline & Regulation of sales and marketing of tobacco (including plain packaging) and alcohol products \\
\hline & $\begin{array}{l}\text { Regulation, public education, and media/non-mass media campaigns on dietary salt (targeting disad- } \\
\text { vantaged population) }\end{array}$ \\
\hline & Regulation and taxation to improve access to healthier diets and to restrict unhealthy food and drink \\
\hline & Policies and programs to improve working conditions and early childhood development \\
\hline \multirow[t]{2}{*}{ Role of civil society } & Monitoring of industries involved in tobacco, alcohol, and unhealthy food and drink \\
\hline & Active involvement in the development of policies to control NCDs \\
\hline \multirow[t]{3}{*}{ Role of academic community } & Research on the burden of NCDs and comparative risks \\
\hline & Research interest in industrial epidemics (tobacco, alcohol, and ultra-processed food and drink) \\
\hline & Development of population approaches to control NCDs \\
\hline
\end{tabular}

tional level, formation of a national NCD commission has been recommended [45]. Because of the multisectoral nature of NCDs, comprehensive and rigorous national strategies and a whole-of-government approach are urgently needed [46], and thus a presidential NCD commission would be appropriate in Korea. A governmental unit for monitoring and evaluation should be established. Development of a national health promotion fund (or the equivalent) has been suggested as the most sustainable funding mechanism for NCD prevention and control [45]. National policies to strengthen the Korean Health Promotion Fund by substantially and regularly increasing the price of tobacco products and starting to impose surcharges on alcohol and unhealthy food products are needed in Korea. Based on the Global Monitoring Framework for NCDs [9], the goals and targets on NCDs and NCD risk factors in the National Health Plan 2020 of Korea should be reviewed and revised and new indicators may also be added.

Many governmental policies should be developed in Korea to achieve a meaningful reduction in NCDs and NCD risk factors and to meet the targets and indicators of the Global Monitoring Framework (Table 4). Many reports have indicated population approaches such as taxation, regulation of marketing and sales, and public education and campaigns are effective measures for controlling NCDs and NCD risk factors $[5,20,36$,
47]. Such population-wide policies have been chosen as 'best buy' interventions that are not only highly cost-effective but also cheap, feasible, and culturally acceptable to implement [5]. Considering the paucity of population-wide policies to control major NCD risk factors in Korea including tobacco and alcohol, and the preponderance of high-risk approaches using screening mechanisms through the national health insurance and public health centers, rigorous population approaches should be further developed in Korea. Aggressive taxation of tobacco and comprehensive smoke-free policies should be implemented right away to further control the use of tobacco. Taxation of alcohol and unhealthy food and drink should be initiated in Korea by including these products as additional items for which the tax is allocated to the National Health Promotion Fund. The Global Strategy to Reduce the Harmful Use of Alcohol [48] should be implemented in Korea. In a recent Lancet paper, Moodie et al. [49] pointed out the lack of evidence supporting the effectiveness of the reliance on industry self-regulation and public-private partnerships in reducing NCD risk factors. They also concluded that public regulation and market intervention are the only evidence-based measures for controlling unhealthy commodities including tobacco, alcohol, and unhealthy food and drink [49]. A comprehensive review of the Health Promotion Act of Korea and associat- 
ed legislation is required to develop more aggressive policies to restrict the sales and marketing of unhealthy commodities. Active and rigorous enforcement of the acts should be also conducted. In addition, public education and both media and non-mass media campaigns especially tailored toward disadvantaged populations need to be developed.

Socioeconomic inequalities in mortality, risk factor prevalence, and treatment of NCDs have been identified [3]. Social determinants including poverty, working conditions, education, housing, and living environment contribute to the development of NCDs and NCD inequalities [39]. Policies to address such social determinants of NCDs should be developed in Korea [50]. Policies and programs to improve early childhood development and working conditions are crucial to effectively address inequalities in NCDs $[3,50]$. The Commission on Social Determinants of Health recommended health equity in all policies, systems, and programs to ensure the reduction of health inequalities by equalizing distributions of power, money, and resources [39]. National strategies with explicit consideration for health and health equity in all policies would help to effectively reduce NCDs and NCD inequalities.

The importance of the roles of civil society and the academic community should also be recognized. Studies on the burden of NCDs and the roles of risk factors (comparative risk assessment) should be conducted in Korea with updated data from death certificates, hospitalization records, and community surveys as well as country-specific disability weighting. Research on the social, economic, and environmental impacts of the NCD burden would be helpful in drawing attention from other sectors (e.g., the economic sector) to the issue. Considering the paucity of detailed information on the activities of unhealthy commodity industries in Korea, mechanisms for monitoring industrial activities related to tobacco, alcohol, and unhealthy food and drink should be developed, especially with the participation of civil society and the academic support of the research community. Furthermore, active involvement by civil society in the development of NCD policies is necessary and research interest in population approaches to controlling NCDs should be pursued.

\section{CONCLUSION}

NCDs are the main contributor to both the disease burden and health inequalities in Korea. International discussions on NCD policies in the UN and the WHO have provided a good opportunity to review governmental NCD policies and further develop rigorous and population-wide policy measures in Korea. Considering the paucity of aggressive population-wide policies to control major NCD risk factors in Korea, rigorous population approaches such as taxation and regulation of unhealthy commodities as well as public education and mass campaigns need to be implemented.

\section{ACKNOWLEDGEMENTS}

I thank Dr. Minsu Ock in the Department of Preventive Medicine, University of Ulsan College of Medicine, for his assistance in calculating age-standardized mortality rates (Figure 1). This paper is based on my plenary presentation at the annual meeting of the Korean Society for Preventive Medicine on April 26, 2013.

\section{CONFLICT OF INTEREST}

The author has no conflicts of interest with the material presented in this paper.

\section{REFERENCES}

1. Lozano R, Naghavi M, Foreman K, Lim S, Shibuya K, Aboyans V, et al. Global and regional mortality from 235 causes of death for 20 age groups in 1990 and 2010: a systematic analysis for the Global Burden of Disease Study 2010. Lancet 2012;380 (9859):2095-2128.

2. Murray CJ, Vos T, Lozano R, Naghavi M, Flaxman AD, Michaud C, et al. Disability-adjusted life years (DALYs) for 291 diseases and injuries in 21 regions, 1990-2010: a systematic analysis for the Global Burden of Disease Study 2010. Lancet 2012;380(9859): 2197-2223.

3. Di Cesare M, Khang YH, Asaria P, Blakely T, Cowan MJ, Farzadfar $\mathrm{F}$, et al. Inequalities in non-communicable diseases and effective responses. Lancet 2013;381(9866):585-597.

4. World Health Organization. The global burden of disease: 2004 update. Geneva: World Health Organization; 2008, p. 1-146.

5. World Health Organization. Global status report on noncommunicable diseases 2010. Geneva: World Health Organization; 2011, p. 1-89.

6. World Health Organization. 2008-2013 Action plan for the global strategy for the prevention and control of noncommunicable diseases [cited 2013 Jun 21]. Available from: http:// 
whqlibdoc.who.int/publications/2009/9789241597418_eng. pdf.

7. World Health Organization. About NCDnet [cited 2013 Jun 21]. Available from: http://www.who.int/ncdnet/about/en/.

8. The NCD Alliance. Who we are [cited 2013 Jun 21]. Available from: http://www.ncdalliance.org/who-we-are.

9. World Health Organization. Final comprehensive global monitoring framework for NCDs [cited 2013 Jun 21]. Available from: http://ncdalliance.org/sites/default/files/rfiles/GMF_Final\%20 Table\%20of\%20Targets.pdf.

10. Alleyne G, Binagwaho A, Haines A, Jahan S, Nugent R, Rojhani $A$, et al. Embedding non-communicable diseases in the post2015 development agenda. Lancet 2013;381(9866):566-574.

11. Eriksen MP, Mackay J, Ross H. The tobacco atlas. 4th ed. New York: American Cancer Society; 2012, p. 44-45.

12. Bloom DE, Cafiero E, Jane-Llopis E, Abrahams-Gessel S, Bloom LR, Fathima S, et al. The global economic burden of noncommunicable diseases. Geneva: World Economic Forum; 2011, p. $1-41$.

13. United Nations. The future we want [cited 2013 Jun 25]. Available from: https://rio20.un.org/sites/rio20.un.org/files/a-conf. 216l-1_english.pdf.

14. World Health Organization. Noncommunicable diseases country profiles 2011. Geneva: World Health Organization; 2011, p. 153.

15. Institute for Health Metrics and Evaluation. GBD arrow diagram [cited 2013 Jun 26]. Available from: http://www.healthmetricsandevaluation.org/gbd/visualizations/gbd-arrow-diagram.

16. Yoon SJ, Bae SC, Lee Sl, Chang H, Jo HS, Sung JH, et al. Measuring the burden of disease in Korea. J Korean Med Sci 2007; 22(3):518-523.

17. Kim EJ, Yoon SJ, Jo MW, Kim HJ. Measuring the burden of chronic diseases in Korea in 2007. Public Health 2013. doi: 10.1016/j.puhe.2012.12.024.

18. Ministry of Health and Welfare. 2009 White paper. Seoul: Ministry of Health and Welfare; 2010, p. 747 (Korean).

19. Yang S, Khang YH, Harper S, Davey Smith G, Leon DA, Lynch J. Understanding the rapid increase in life expectancy in South Korea. Am J Public Health 2010;100(5):896-903.

20. Ezzati M, Riboli E. Can noncommunicable diseases be prevented? Lessons from studies of populations and individuals. Science 2012;337(6101):1482-1487.

21. National Cancer Information Center. Cancer incidence [cited 2013 Jun 26]. Available from: http://www.cancer.go.kr/mbs/ cancer/subview.jsp?id= cancer_040101000000 (Korean).

22. Jung KW, Won YJ, Kong HJ, Oh CM, Seo HG, Lee JS. Cancer statistics in Korea: incidence, mortality, survival and prevalence in 2010. Cancer Res Treat 2013;45(1):1-14.

23. Hong JS, Kang HC, Lee SH, Kim J. Long-term trend in the incidence of acute myocardial infarction in Korea: 1997-2007. Korean Circ J 2009:39(11):467-476.

24. Kim RB, Kim BG, Kim YM, Seo JW, Lim YS, Kim HS, et al. Trends in the incidence of hospitalized acute myocardial infarction and stroke in Korea, 2006-2010. J Korean Med Sci 2013;28(1): 16-24.

25. Kim DJ. The epidemiology of diabetes in Korea. Diabetes Metab J 2011;35(4):303-308.

26. Kim DS, Kim YS, Jung KS, Chang JH, Lim CM, Lee JH, et al. Prevalence of chronic obstructive pulmonary disease in Korea: a population-based spirometry survey. Am J Respir Crit Care Med 2005;172(7):842-847.

27. Yoo KH, Kim YS, Sheen SS, Park JH, Hwang YI, Kim SH, et al. Prevalence of chronic obstructive pulmonary disease in Korea: the fourth Korean National Health and Nutrition Examination Survey, 2008. Respirology 2011;16(4):659-665.

28. Khang YH, Lynch JW, Kaplan GA. Health inequalities in Korea: age- and sex-specific educational differences in the 10 leading causes of death. Int J Epidemiol 2004;33(2):299-308.

29. Jung-Choi K, Khang YH, Cho HJ. Socioeconomic differentials in cause-specific mortality among 1.4 million South Korean public servants and their dependents. J Epidemiol Community Health 2011;65(7):632-638.

30. Kim CW, Lee SY, Moon OR. Inequalities in cancer incidence and mortality across income groups and policy implications in South Korea. Public Health 2008;122(3):229-236.

31. Yim J, Hwang SS, Yoo KY, Kim CY. Contribution of income-related inequality and healthcare utilisation to survival in cancers of the lung, liver, stomach and colon. J Epidemiol Community Health 2012;66(1):37-40.

32. Ministry of Health and Welfare; Korea Centers for Disease Control and Prevention. 2009 Korea health statistics: findings of Korea National Health and Nutrition Examination Survey IV-3 (2009). Seoul: Ministry of Health and Welfare; 2010, p. 1-588 (Korean).

33. Kim YM, Jung-Choi K. Socioeconomic inequalities in health risk factors in Korea. J Korean Med Assoc 2013;56(3):175-183 (Korean).

34. Cho HJ. Equity in health care: current situation in South Korea. J Korean Med Assoc 2013;56(3):184-194 (Korean). 
35. Khang YH, Yang S, Cho HJ, Jung-Choi K, Yun SC. Decomposition of socio-economic differences in life expectancy at birth by age and cause of death among 4 million South Korean public servants and their dependents. Int J Epidemiol 2010; 39(6):1656-1666.

36. Beaglehole R, Bonita R, Horton R, Adams C, Alleyne G, Asaria P, et al. Priority actions for the non-communicable disease crisis. Lancet 2011;377(9775):1438-1447.

37. Lim SS, Vos T, Flaxman AD, Danaei G, Shibuya K, Adair-Rohani $\mathrm{H}$, et al. A comparative risk assessment of burden of disease and injury attributable to 67 risk factors and risk factor clusters in 21 regions, 1990-2010: a systematic analysis for the Global Burden of Disease Study 2010. Lancet 2012;380(9859): 2224-2260.

38. Ikeda N, Inoue M, Iso H, Ikeda S, Satoh T, Noda M, et al. Adult mortality attributable to preventable risk factors for noncommunicable diseases and injuries in Japan: a comparative risk assessment. PLoS Med 2012;9(1):e1001160.

39. Commission on Social Determinants of Health. Closing the gap in a generation: health equity through action on the social determinants of health. Geneva: World Health Organization; 2008, p. 1-224.

40. Khang YH, Lynch JW, Yang S, Harper S, Yun SC, Jung-Choi K, et al. The contribution of material, psychosocial, and behavioral factors in explaining educational and occupational mortality inequalities in a nationally representative sample of South Koreans: relative and absolute perspectives. Soc Sci Med 2009; 68(5):858-866.

41. Khang YH, Lynch JW, Jung-Choi K, Cho HJ. Explaining agespecific inequalities in mortality from all causes, cardiovascular disease and ischaemic heart disease among South Korean male public servants: relative and absolute perspectives. Heart
2008;94(1):75-82.

42. Lynch J, Davey Smith G, Harper S, Bainbridge K. Explaining the social gradient in coronary heart disease: comparing relative and absolute risk approaches. J Epidemiol Community Health 2006;60(5):436-441.

43. Kivimäki M, Shipley MJ, Ferrie JE, Singh-Manoux A, Batty GD, Chandola T, et al. Best-practice interventions to reduce socioeconomic inequalities of coronary heart disease mortality in UK: a prospective occupational cohort study. Lancet 2008; 372(9650):1648-1654.

44. Center for Health and Social Change. Exploring the UN NCD Summit [cited 2013 Jun 28]. Available from: http://www.chsc. or.kr/xe/?document_srl=69567 (Korean).

45. Beaglehole R, Bonita R, Horton R. Independent global accountability for NCDs. Lancet 2013;381(9867):602-605.

46. Bonita R, Magnusson R, Bovet P, Zhao D, Malta DC, Geneau R, et al. Country actions to meet UN commitments on non-communicable diseases: a stepwise approach. Lancet 2013;381 (9866):575-584.

47. World Bank. The growing danger of non-communicable diseases: acting now to reverse course. Washington, DC: World Bank; 2011, p. 1-14.

48. World Health Organization. Global strategy to reduce the harmful use of alcohol. Geneva: World Health Organization; 2010, p. 1-38.

49. Moodie R, Stuckler D, Monteiro C, Sheron N, Neal B, Thamarangsi $\mathrm{T}$, et al. Profits and pandemics: prevention of harmful effects of tobacco, alcohol, and ultra-processed food and drink industries. Lancet 2013;381(9867):670-679.

50. Kim MH, Lee J. Current status of policy developments in tackling health inequalities and the next steps to be taken in Korea. J Korean Med Assoc 2013;56(3):206-212 (Korean). 